1 Social capital in post-disaster recovery trajectories: insights from a

2 longitudinal study of tsunami-impacted small-scale fisher

3

4

5

6

7

\section{organizations in Chile}

\author{
Andrés Marín ${ }^{a, b} ;$ Örjan Bodin ${ }^{a}$; Stefan Gelcichc; Beatrice Crona ${ }^{a, d}$
}

\title{
AFFILIATIONS
}

${ }^{a}$ Stockholm Resilience Centre, Stockholm University, Stockholm -Sweden.

${ }^{\mathrm{b}}$ Centro de Estudios del Desarrollo Local y Regional, Universidad de Los Lagos, Osorno -Chile.

${ }^{\mathrm{c}}$ Departamento de Ecologia, Center of Applied Ecology and Sustainability (CAPES) and Centro de Conservacion Marina, Pontificia Universidad Catolica de Chile, Santiago -Chile.

${ }^{\mathrm{d}}$ Global Economic Dynamics and the Biosphere, Royal Swedish Academy of Sciences, Stockholm -Sweden.

\section{ACKNOWLEDGEMENTS}

The authors thank the fisher leaders who kindly accepted to participate in the study and also SERNAPESCA professionals in Tomé, Talcahuano, and Coronel who agreed to be interviewed. AM is funded by Stockholm Resilience Centre (core funding) and Becas-Chile CONICYTGobierno de Chile; ÖB acknowledges support from the strategic research program Ekoklim at Stockholm University; SG thanks Financiamiento Basal FB-0002, Nucleo-Milenio initiative P10-033 and NC-120086 from the Ministerio de Economia; BC's contribution was funded by the Erling-Persson Family Foundation through the Global Economic Dynamics and the Biosphere Programme, the Royal Swedish Academy of Sciences, Sweden (BC).

\section{ABSTRACT}

Increased likelihood and severity of coastal disasters in the $21^{\text {st }}$ century represent major threats for coastal communities' resource management capacity and livelihoods. Disaster research has frequently looked for singular factors explaining why some communities are more resilient and better equipped to cope with and recover from disasters. This study draws on Chile's 2010 tsunami to evaluate the effects of both internal (social capital) and external (level of damage and isolation) factors on fishing communities' recovery trajectories. Using qualitative comparative analysis (QCA) we assess how the concurrency of conditions explains fisher organization responses. By operationalizing social capital as the social networks developed for co-management, we also evaluate whether social capital developed for natural resource management can help communities overcome post-disaster challenges. Results show that the level of linking social capital is critical in determining postdisaster trajectories. While maintained or increasing levels of social capital is indispensable for positive trajectories to occur, a common denominator for less desirable post-disaster 
recovery trajectories is a low or reduced level of social capital. However, external factors, such as the amount of damage and geographical isolation, are also important in determining recovery trajectories, indicating the limits of relying solely on social relations for recovery. These concurrent factors can amplify or reduce the importance of supportive relationships. Understanding the implications of complex interplay between social capital and external factors for community recovery in response to coastal disasters can inform the design of more effective and efficient responses and policies in Chile and more broadly. Furthermore, social capital developed for the purpose of co-management of natural resources can actually promote desirable post-disaster trajectories.

Keywords: coastal disasters, livelihoods, longitudinal, social networks, Qualitative Comparative Analysis, human dimensions, tsunami

\section{INTRODUCTION}

More frequent and severe disasters are forecasted for the $21^{\text {st }}$ century due to climate and other global environmental changes. These are likely to have greater impacts on coastal zones and dramatic consequences for fishing households and communities (Adger et al. 2005; Costanza and Farley 2007; Smith 2013). Poverty and high dependence on diminishing natural resources imply low abilities to recover, which make small-scale fishing communities one of the most vulnerable groups to coastal disasters and perturbations (Pomeroy et al. 2006). In the last decade, for instance, tsunamis in South Asia, Chile and Japan have devastated entire communities, port infrastructure, fishing fleets and coastal ecosystems, threatening the livelihoods of millions of people (Miller et al. 2006; Marín et al. 2010; Palermo et al. 2013; Mimura et al. 2011). In general, fisheries and local communities recover from catastrophic events in the long-term, but show uneven capacities to respond. While some groups are able to react quickly and adapt to the new conditions, many have a hard time trying to normalize their lives and risk losing their livelihoods or moving towards unsustainable practices such as overfishing (Pomeroy et al. 2006; Santha 2015). Understanding what makes a difference for fishing communities in the aftermath of coastal disasters can therefore inform the design of more equitable and sustainable livelihood recovery strategies.

What makes communities better or worse prepared to respond and recover from extreme perturbations? Disaster research has largely drawn on resilience and vulnerability concepts to address this question (Manyena 2006). Resilience refers broadly to the capacity of systems to absorb recurrent disturbances so as to retain essential structures, processes, identity and feedbacks (Walker et al. 2004; Adger et al. 2005). Disaster resilience, in particular, has been defined as "the ability to prepare and plan for, absorb, recover from, or more successfully adapt to actual or potential adverse events" (National Research Council 
2012, p.16). In the face of a disaster, the resilience approach focuses on the internal or intrinsic factors of systems that lead to more or less capacity to respond to risks and adapt to change. Vulnerability, by contrast, reflects the level of exposure to risk. It has been defined as "the state of susceptibility to harm from exposure to stresses associated with environmental and social change" (Adger 2006, p.1). Vulnerability also has been associated with the circumstances of a person or group that determine their ability to withstand and recover from the impact of perturbations (Blaikie et al. 2004, Adger 2006). Disaster vulnerability reflects the likelihood to be damaged, which varies in time and space, and among different social groups (Cutter et al. 2003). Unlike the resilience concept, the vulnerability approach highlights external or contextual factors that determine the exposure of a system to disasters and its possibilities to respond and recover.

Despite their differences, resilience and vulnerability are complementary concepts. Integrative approaches to the study of disasters attempt to understand how internal and external factors simultaneously determine processes and outcomes after a major shock (Berkes 2007; Turner 2010; Maru et al. 2014; Cutter et al. 2014). In this study of the Chilean 2010 tsunami and its impacts on the small-scale fishery in the BioBio region (Fig. 1), we adapt this integrative approach to explore the interplay between internal factors related to resilience (social capital; hereon $\mathrm{SC}$ ) and external factors related to vulnerability (extent of the damage and geographic isolation) in affecting fisher organizations' post-disaster recovery trajectories.

SC broadly captures a group or an individual's ability to act and make use of various types of resources through the existence of social relations, shared norms and mutual trust (Coleman 1988; Krishna 2002), and has been regarded by some as a key determinant of disaster recovery highly dependent on actors' capacities (Munasinghe 2007; Aldrich 2010; Aldrich 2011a). In the aftermath of disasters, the underlying networks between and among individuals, groups and organizations are believed to channel crucial resources and information that facilitate collective action and more prompt and sustainable recovery (Nakagawa and Shaw 2004; Aldrich 2012). Other authors have claimed that recovery is determined by external factors beyond the control of impacted communities, such as the extent of damage suffered and the level of isolation, which (Haas et al. 1977; Régnier et al. 2008). So far, studies have analyzed the individual effect of internal and external factors on disaster recovery, but few have explored whether these effects are contingent to another. Yet better understanding of current problems in social-ecological systems greatly demands that we (re)think about complex causal pathways and the toolbox of methods and approaches used (Young et al. 2006). Consideration of concurrent and interacting rather than single factors can have important implications for more effective resource allocation and post-disaster recovery policies.

In this study we investigate if and how SC -in combination with the levels of damage and geographic isolation - determines fishing organizations' ability to recover and innovate in 
response to a tsunami disaster. We hypothesize that this capacity is fundamental to postdisaster recovery and, in combination with other internal and external factors, will be critical in determining community resilience and vulnerability (Pelling and High 2005; Adger 2012). The research draws on semi-structured and in-depth interviews with the leaders of fisher organizations and fishery authorities carried out before and after the 2010 Chilean earthquake and tsunami. In the following sections we first discuss what post-disaster recovery implies in the context of resource-based communities and the potential factors behind it; second, we introduce Chile's small-scale fisheries and the coastal disaster that struck the country in 2010; third, we describe the data collection process and the tools employed, the operationalization of the outcome and explanatory variables, and our approach to data analyses. We then present and discuss our findings and limitations of the research.

\section{Post-disaster recovery trajectories: bouncing back and beyond}

Disasters can suddenly affect the livelihoods of small-scale natural resource users (Marín et al. 2014). Not only can they alter ecosystems on which people rely, but they can also destroy infrastructure and technology used to exploit and manage those ecosystems. A common expectation after a disaster is to rebuild, recover, or return to the normal (Leitch and Bohensky 2014). In the literature, this notion is normally referred to as the capacity of a system to "bounce back" to a previous state (Manyena 2006). Bouncing back can be problematic when applied to disasters, because: 1) depending on the extent of the damage or perturbation, returning to a previous condition might be impossible (Zanuttigh 2014); 2) in some contexts, returning to a state that is vulnerable and unsustainable can be highly undesirable (Pomeroy et al. 2006).

For many resource based communities, including small-scale fisheries, recovering from abrupt devastating events normally implies the compounded challenge of not only recovering what was lost, but also addressing old and persistent problems, vulnerabilities and slow-paced changes and uncertainties (Pomeroy et al. 2006; Régnier et al. 2008). Thus, measuring exactly how much fisher organizations have recovered at a particular point in time is less important than understanding post-disaster recovery trajectories (Masten and Obradovic 2008). This allows identifying both the ability to bounce back as well as improving ones development path. Without ignoring the harmful side of disasters, authors have highlighted that they can also open windows of opportunity for positive transformation (Blaikie et al. 2004; Goldstein 2008; Olsson and Galaz 2011; Carpenter et al. 2012). More desirable trajectories, in this sense, include fishers innovating and diversifying their livelihoods (Alexander et al. 2006) and proactively responding and adapting to increasingly different or uncertain conditions (e.g., in marine ecosystems, climate, and global markets) that threaten the sustainability of small-scale fisheries (Adger 2003). The capacity to 
innovate plays a critical role in achieving recovery and moving forward. Whether identifying and exploring new pathways or finding and navigating the way back to a previous state, people and groups are likely to benefit from having the capacity to be creative and devise alternative solutions within new and/or modified contexts created by the disaster.

\section{Social capital and other explanatory factors of post-disaster recovery}

A long-standing research question-common to disaster, human development and socialecological studies-concerns the factors that explain and predict individual and collective capacity to respond to and recover from disasters or other shocks leading to radical change (Skoufias 2003; Diamond 2005; Gunderson 2010; Aldrich 2012a). In the context of natural resource user communities, studies have proposed different explanations, such as the extent of the damage (Haas et al. 1977), the levels of education of people (Frankenberg et al. 2013), pre and post-disaster ecological conditions (Miller et al. 2006), the existence of an enabling business environment (Régnier et al. 2008), and the implementation and type of responsive policies (Ingram et al. 2006). More recently, studies have stressed social networks and SC as the main engine for long-term post-disaster recovery (Pelling and High 2005; Munasinghe 2007; Aldrich 2010), suggesting that the quality of the social fabric in which individuals and groups are embedded is more important than other social features (e.g., economic conditions) and external determinants (e.g., amount of damage) in explaining successful recovery (Aldrich 2011a). Without neglecting its importance, others have suggested a more nuanced consideration of the actual role of SC in disaster recovery (Aldrich 2011b; Gill 2014; Tierney 2013).

$\mathrm{SC}$ is a multifaceted concept. Broadly speaking, it refers to the existence of social networks generally characterized by shared norms, trust and reciprocity, which lead to positive results for people (Bourdieu 1986, Coleman 1988, Putnam 2000). Higher levels of SC have been correlated with multiple desirable societal outcomes, such as improved public health (Szreter and Woolcock 2004), enhanced economic development (Krishna 2002), and more sustainable management of natural resources (Pretty 2003). Other scholars have warned against the sometimes negative consequences of SC, for instance when strong SC of the elite can further marginalize people in the periphery (Portes and Landolt 2000; Aldrich 2011). Certainly, it is important not to consider SC a silver bullet, but rather to analyze its potential contribution to better understand and enable post-disaster recovery processes. Despite the diversity of SC definitions, social networks are a key component in all of them and provide common ground for the empirical study of SC (Borgatti et al. 1998; Bodin and Crona 2009). We adopt this network approach to defining and operationalizing SC, emphasizing the resources embedded in the social structure and differentially accessed and/or mobilized in purposive actions by social actors (Lin 2001; Bodin and Crona 2008). Access and mobilization of information and resources (e.g., financial, support and ideas) in the aftermath of disasters has been hypothesized as a key boost of faster and better recovery (Aldrich 2012). 
Three types of network SC have been applied in the study of local and resource user communities: bonding (i.e., intra group/community relationships), bridging (i.e., horizontal relationships between different groups/communities), and linking SC (i.e., relationships between local groups/communities and actors in higher levels of political, economic, or social hierarchy (Woolcock 2001; Szreter and Woolcock, 2004; Grafton 2005; Marín and Berkes 2010). Although all three dimensions are important, linking SC has been found to play a critical role in reducing people's livelihood vulnerabilities and in responding to disasters and crises (Nakagawa and Shaw 2004; Tierney 2013; Pelling and High 2005). When widespread destruction affects the local level, communities are more likely to satisfy their needs if they can obtain resources and support from other places. The ability to leverage those resources increases if the community has diverse and strong trustful relationships with higher-level organizations (i.e., high level of linking SC). Yet linking SC tends to be scarce in more vulnerable communities (Woolcock 2002), and the lack thereof can lead to increased social inequalities and undermined capacities to act collectively (Pelling and High 2005).

External factors are likely to interact with SC to affect post-disaster recovery. Some of these highlighted in the literature, such as recovery policies and business environments, tend to be highly constant when focusing on the local and regional levels. By contrast, levels of damage and geographical isolation allow fine-grained differentiation among local resource user communities that are otherwise very homogenous. Both factors represent potential obstacles to the access and flow of resources and information between the local level and higher levels where critical assets for recovery can be obtained (e.g., financial, human, knowledge). Among other issues, transaction costs can vary as a result (e.g., search and information, bargaining, and policing and enforcement costs; see Dahlman 1979). For instance, level of damage reflects the extent of material loss and the associated investment costs of recovery. While some authors have found that higher damage delays and makes recovery processes more difficult (Kates and Pijawka 1977), others have claimed that higher damage attracts faster technological investment (see Aldrich 2012a).

Geographical isolation reflects the amount of effort required to bring in disaster relief, access information, and establish interpersonal communication among actors and has been correlated with economic marginalization and higher vulnerability to disasters (Pomeroy et al. 2006). For impacted fishers, isolation relates to how far they have to go (and how costly it is) to present their needs and negotiate potential support from actors at other levels. For government agencies, donors and other actors, levels of damage and isolation of devastated communities imply the need to assess how much money is required to produce an impact and how much effort will be required to implement the collaboration and obtain a return. conditions, its expected benefits are realized in disaster recovery trajectories. By evaluating 
the potential effects of both internal (i.e., SC) and external (level of damage and geographical isolation) factors of fishing organizations' recovery trajectories, we aim to investigate to what extent the expected benefits of cross-scale social relationships are more or less effective in different contexts that are beyond the control of local communities. Second, we examine the potential effect of changing SC on post-disaster trajectories using longitudinal data. Although many studies have highlighted the importance of SC in recovering from disasters, there is limited understanding of the temporal dimension of this relationship. Disasters represent milestones in people's lives, dividing time into a before and after. Furthermore, disasters can indirectly affect social relationships among the impacted (Costanza and Farley 2007), thus changing SC levels and effectiveness. Third, we examine whether cross-scale social relationships, developed for a specific purpose (namely natural resource management; see Marín et al. 2012), can potentially be activated and utilized to promote post-disaster recovery. Aldrich (2012) and others have emphasized the importance of investing not only in physical but also in social infrastructure to produce sustainable recovery outcomes. In this study we explore whether the existence of and involvement in a co-management system, conceived as a social infrastructure, may help fishing communities in responding and recovering after a disaster.

\section{RESEARCH SETTING}

The BioBio Region, located in central-south Chile, is the second most important region for national artisanal fisheries in general, and for the small-scale benthic oriented subsector in particular (i.e., users targeting bottom-dwelling marine organisms). In 2010 a massive earthquake and tsunami hit this part of the country, severely impacting small-scale fisheries and livelihoods. As we explain below, after an abrupt decline in landings, the benthic subsector started to recover its normal fishing capacity in 2011. However, four year after the disaster, individual fisher organizations were performing unevenly. While some of them were able to respond quickly and effectively and use their innovative and adaptive ability to embark on positive recovery trajectories, others were stagnated or in a process of decline with likely negative impacts on their livelihoods. Here, we first characterize fishing communities and organizations under study, their livelihoods and relationships with coastal ecosystems. Then, we describe the tsunami event and its impacts and consequences on fishing organizations.

\section{Small-scale fishing communities and their livelihoods}

More than 23,500 people and 240 fisher organizations are listed in the artisanal fishery register in BioBio, representing 26 percent of the national artisanal fishery workforce (SERNAPESCA 2013b). In 2013, marine resource landings in the region were more than 244 thousand tons, accounting for 20 percent of the national artisanal catch. But Chilean 
artisanal fisheries are very heterogeneous, and various subsectors can be identified based on the type of vessels (e.g., four categories from less than 8 and up to 18 meters long), navigation and fishing technology employed (e.g., from no technology at all, to GPS, sonar and purse seiners), and the species extracted (e.g., out of 67 species of fish, 30 of mollusks, more than 20 of crustaceans, and 13 of seaweed).

The small-scale benthic oriented subsector refers to boat owners, fishers and hookah divers operating from boats of up to 8-meter-long, equipped with off board engines and air compressors, and also includes inshore and near-shore gatherers operating either with or without vessels. This subsector targets multiple species and mostly, but not exclusively, benthic resources such as mollusks (e.g., loco/Concholepas concholepas, navajuela/Tagelus dombeii and huepo/Ensis macha), crustaceans (e.g., jaiba limón/Cancer porter and jaiba peluda/Cancer setosus) and seaweed (e.g., luga negra/Sarcothalia crispata and huiro negro/Lessonia nigrescens).

Management and Exploitation Areas for Benthic Resources (hereafter MEABR) for the smallscale fishery were established by Law since the 1990s to halt overexploitation trends and to foster the sustainable use of benthic resources (Castilla 1994; Gelcich et al. 2010). The MEABR is a form of co-management system, in which the state transfers exclusive territorial user rights to organized fisher organizations over a portion of coastal seabed and the resources therein. The opportunity to obtain a MEABR was an important driver for the organization of fishers, divers and gatherers into unions, cooperatives and associations (collectively referred to in this paper as 'fisher organizations', from hereon FO), and for the collective management of resources (Payne and Castilla 1994; Gelcich et al. 2005). The MEABR system has also led to more permanent and formalized relationships between resource users and the state and other agencies (Schumann 2007; Marín and Berkes 2010) and represents a key pillar of small-scale fisheries and coastal management along Chile's coasts (Gelcich et al. 2010).

Caletas (coves in English; see Castilla et al. 1998) refers to landing and mooring sites and in rural areas also to the fishing villages that develop around them (Aburto et al. 2009). Caleta facilities normally include basic port infrastructure, stowage for equipment and gear, office/meeting room, and fish vending stalls. Some fisher organizations have, with support from the state, improved their caletas to take advantage of tourism by e.g. running restaurants, museums, or seafood or handicrafts stalls. Other have gone even further and implemented small-scale aquaculture or processing plants projects. In BioBio, there are 81 official caletas.

\section{The 2010 tsunami, its impacts and consequences}


At dawn on February 27, 2010, an Mw 8.8 earthquake befell south-central Chile, the world's $6^{\text {th }}$ largest instrumentally recorded earthquake. The epicenter and the rupture zone, located in the Pacific Ocean, generated a tsunami that hit ca. $600 \mathrm{~km}$ of Chile's coastline. The tsunami caused 156 fatalities and major destruction along the coast and a total economic loss estimated, together with the earthquake, of USD 30 billion.

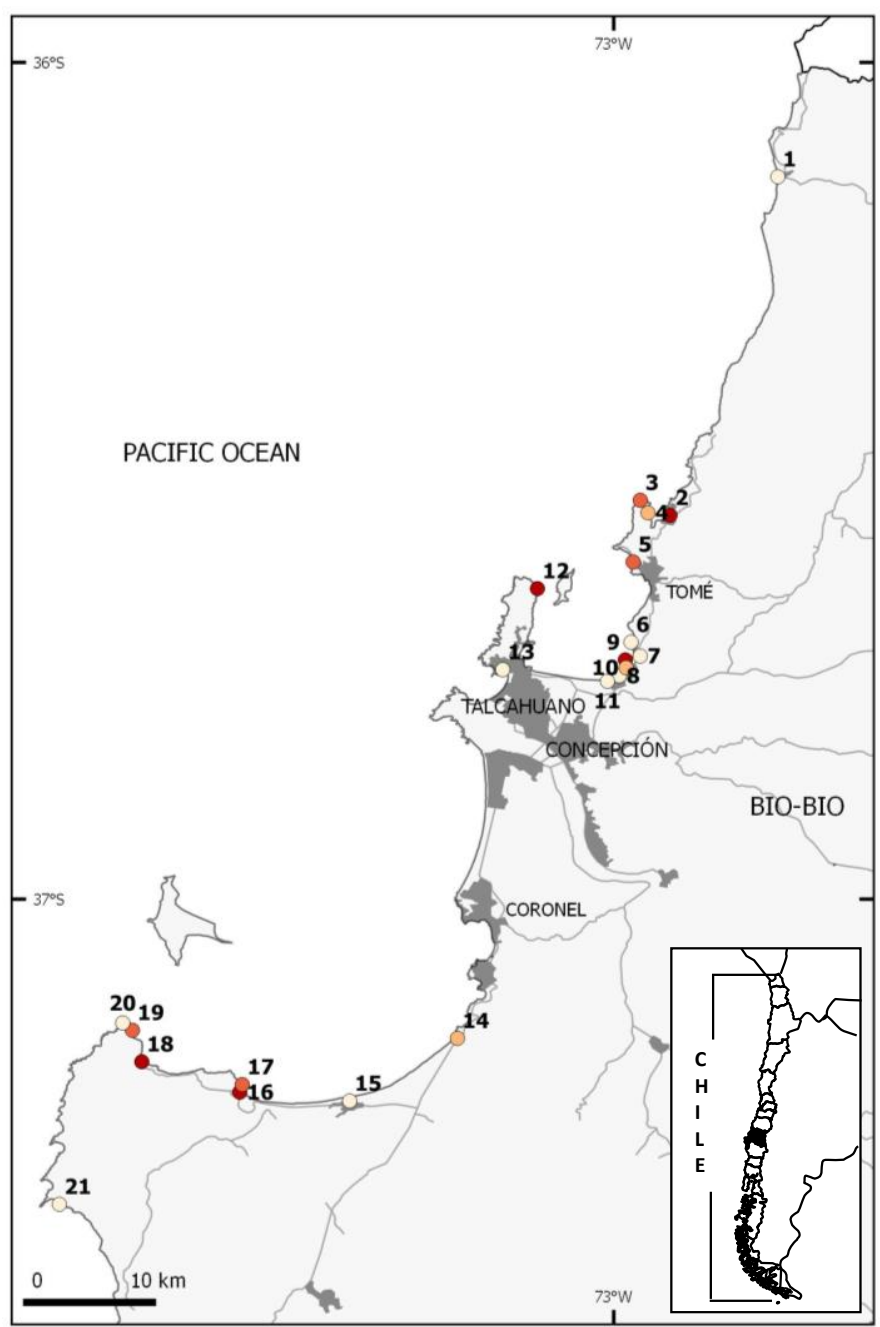

Figure 1: Area of study and referential location of the 21 fisher organizations (FO; their names are omitted for confidentiality); colors express the level of damage (i.e., darker colors = higher damage); grey patches show urban areas; lines stand for main highways.

Tsunami local impacts were highly variable along the BioBio coast resulting from differences in local geomorphology and bathymetry of the coast and continental shelf, and from complex patterns of tsunami wave propagation (Vargas et al. 2011). The largest impacts were observed in U-shaped and northward facing coves, bays, and gulfs (Fritz et al. 2011; Morton et al. 2011). Under normal climatic conditions these areas are natural shelters and excellent mooring and landing sites, and have therefore been traditionally selected as fishing caletas and coastal settlements (see Fig. 1). However, during the tsunami they became highly hazardous zones while nearby localities with more open shorelines experienced less 
impact (Vargas et al. 2011; Morton et al. 2011). Fishing caletas and organizations in the region thus suffered unequal impact to their infrastructure and assets.

In BioBio, the power of repeated tsunami waves represented an abrupt shock for the smallscale fishery, with up to $60 \%$ loss and damage of fishing capacity in impacted areas, including damage to vessels, gear and equipment, port infrastructure, and productive and commercial infrastructure (Marín et al. 2010). In 2010 total small-scale landings of mollusks, seaweed and crustaceans in BioBio were 52, 66 and 55 percent lower than in 2009, respectively (SERNAPESCA 2009, 2010). This decline is explained by the reduction in fishing capacity, the hesitancy of fishers to return to work while a perception of risk remained, and to a minor extent by direct ecological effects of the disaster, including loss of marine resources (e.g., especially mollusks and seaweed) and habitats (e.g., rocky reefs) associated with coastal uplift generated mostly in the southern part of the region (Castilla et al. 2010; Jaramillo et al. 2012).

During 2010, multiple public and private, national and international aid programs provided fishers with new or repaired vessels and equipment to return to the sea, and one year after the event, the fishery showed symptoms of recovery. Mollusk and crustacean extractions in 2011 were 86 and 129 \% higher than in the year of the disaster. In 2012, mollusks and crustacean landings increased further while seaweed resources slowly rebounded (after a 13\% decrease in 2011). After a dramatic decay attributable to the 2010 disaster, four years later resource extractions seemed recovered showing normal annual variation.

\section{METHODS}

\section{Data collection}

Between May and December 2013, semi-structured interviews were carried out with the elected leaders of 21 small-scale fisher organizations in BioBio (Fig. 1). The sample of organizations was purposive, and the criterion was to replicate the sample obtained in a previous study in 2008 (Marín et al. 2012). For these organizations, pre-disaster base-line information on SC, resource management performance and livelihoods was available, allowing for the inclusion of a longitudinal component into the analysis. The set of organizations studied is also representative of the diversity of caletas in continental BioBio in terms of geographical location and local settings (e.g., urban/rural cases). For confidentiality we omit the names of the organizations; but they are available upon request for research purposes.

We selected the leaders as representatives of and qualified informants on their organizations since most affairs that involve relationships between the organization and 
higher-level actors involve the direct participation of leaders. Besides their role as leaders for co-management structures, they were also instrumental in the emergency and recovery phases after the tsunami. The survey included questions about the impacts suffered by the organization and its members, the level of material recovery, and the social relationships perceived as facilitating MEABR functioning and caleta recovery in the aftermath of the disaster.

We also conducted 5 semi-structured interviews with SERNAPESCA officials to learn about general trends in regional small-scale fisheries and the MEABR system, and to obtain an external case-by-case assessment of fisher organizations' post-disaster trajectories, namely the outcome variable. These professionals have on average more than 8 years of field experience working with fisher organizations and resource landing data in this region. Their broad perspective allows them to provide comparative appraisals among cases. We regard SERNAPESCA officials as knowledgeable informants about pre and post disaster conditions of our study units.

In addition to the systematic data collection described above, some of the authors were involved in fieldwork and empirical research associated with social and ecological impacts of the 2010 earthquake and tsunami since shortly after the event (Marín et al. 2010; Marin et al. 2012; Marín et al. 2014). This experience is part of the knowledge base applied in this study.

\section{Operationalization of the outcome variable}

We aim to explain why fisher organizations exhibit differences trajectories with regard to marine resource use and securing their members' livelihoods, four years after the tsunami. This outcome variable aims to capture trends in collectively performed productive activities in relation to resources use, management and commercialization. Post-disaster recovery has been described as phases where challenges and trade-offs exist between the short, mid and long term (Ingram et al. 2006; Régnier et al. 2008; Thornburn 2009). Our interest is to understand the trajectories including mid-term (i.e livelihood recovery) and long-term (fishery development) phases.

To operationalize the outcome variable we developed an ordinal scale of five possible trajectories ( $5=$ =relatively most desirable to $1=$ relatively least desirable) any resource user organization may show after a destructive disaster, summarized in Table 1. The basic assumption is that shortly after the tsunami every impacted organization began its attempt to resume and normalize their activity. We termed this post-disaster starting point recovering trajectory. After 4 years, every organization would have either remained in this effort (scoring 3) or moved into a different trajectory. Some organizations would have recovered to a similar condition they had before the tsunami, here termed the normalization 
trajectory (scoring 4), or taken the opportunity to do new and/or different activities, termed the innovation trajectory (scoring 5). Other organizations would have had less desirable post-disaster recoveries such as lack of continuity and dynamism in their recovery efforts (stagnation trajectory; scoring 2), or loss of the capacities and qualities they had before (recession trajectory; scoring 1 ).

Based on this reasoning, SERNAPESCA informants were asked to assess and assign a score to each fisher organization in their jurisdiction using a card that was presented to them with the names of the five trajectories. When more than one informant was knowledgeable about the recent history of one organization, average scores were considered in the analysis. When asked to justify their positive assessments, informants mentioned new initiatives to restock or cultivate resources in MEABR, the reimplementation of a destroyed seaweed processing plant, or the ability of the leadership to draw on gender issues to leverage external support and funding for the organization. Arguments for negative valuations include the inability to recover to former fishery production levels, lack of motivation among organization members, or failure to take advantage of available opportunities.

Fisher leaders were also asked to self-assess their trajectories using the same rationale and scale. Results from external and self-assessments were positively (0.55) and significantly correlated $(p<.0001)$, confirming that the scale made sense to informants, and that fisher leaders can provide reliable information about their organizations and caletas.

\section{Operationalization of explanatory factors}

The selection of the explanatory factors of post-disaster recovery for this study is based on existing literature, and by taking the specific context of the study area into account. As discussed above, the emphasis on SC represents a recent turn in the study of post-disaster recovery (Pelling and High 2005; Munasinghe 2007). In addition, it has been found in recent studies that SC is important for fishing communities in Chile for obtaining positive resource management and livelihood outcomes (Marín et al. 2012; Rosas et al. 2014). These two arguments suggest that SC is an important factor to be considered in our study. In turn, consideration of levels of damage and isolation as determinants of recovery is common in disaster research (Kates and Pijawka 1977; Pomeroy et al. 2006). In addition, our study cases show variability in these factors, therefore they provide an opportunity to tease out whether and how they might influence the outcome. Below we present the operationalization of these factors.

Pre-disaster linking social capital (LINK08): In 2008, using a roster of 26 institutions and organizations (operating at the regional, national and international levels) previously identified by means of exploratory interviews and secondary information, we asked fisher leaders to identify the actors with which they have established facilitating relationships for 
the development of collaborative management of MEABR (see Appendix 2 in Marín et al. 2012). These relationships include, for instance, connections with fishery authorities to obtain extraction allowances, with university researchers and fishery consultants to get advice and assistance, and with buyers/traders to obtain economic revenues. Then, interviewees were asked to express the importance of nominated actors for MEABR development using a 1 (=not important at all) to 4 (=very important) scale presented to them in a card. To make sure that only truly relevant relationships are counted, and to filter out responses provided by informants with more lenient criteria, we considered only "important" and "very important" relationships for the assessment of linking SC.

The measurement of linking SC is based on the egocentered network approach (Lakon et al. 2008) and the degree centrality measure (Borgatti and Everett 1998). In network terms, each fisher organization is an ego, which has facilitating relationships with a set of comanagement counterparts, called alters, as defined by its representing leader. Drawing on that specific set of relationships, degree centrality of egos refers to the number of existing relationships as a proportion of the theoretical maximum number of relationships (i.e., the 26 actors in the roster).

Post-disaster linking social capital (LINK13): Using the same survey questions and operationalization we measured linking SC of fisher organizations in 2013 (i.e., four years after the tsunami). SC and associated networks are relatively stable but not fixed over time. Individuals and groups can strengthen, increase and diversify their positive relationships with others (i.e., enhancing SC), increasing thereby their access to opportunities. But they can also ignore and lose beneficial relationships (e.g., reducing SC), missing chances to access key resources and information. Our purpose is not to explain changes in SC, but to include the variation in SC as a potential intervening cause of post-disaster trajectories.

Different fisher organizations hold different levels of linking SC, ranging between those that have one relevant facilitating relationship to those with more than 15 . Similarly, fisher organizations' levels of SC changed in time 2008-2013 such that 10 organizations increased, 7 maintained and 4 decreased their degree centrality levels.

SC studies risk falling into problems of endogeneity and circular reasoning (Mouw 2006), for instance, when the indicators used for measuring SC are in essence closely correlated with those used as measurements of its expected outcomes. We avoid endogeneity by: 1) relying on two different sources of information, namely the experiences and perceptions of fisher leaders and fishery authority officials to assess social capital and recovery, respectively; 2 ) framing the assessment of both variables in two different (but still associated) domains, namely SC in the specific context of co-management, and recovery in the broader context of multiple fishing livelihood activities. 
Level of damage (DAM): As explained above, caletas and fisher organizations can possess variable facilities and assets and the impacts of the tsunami in BioBio were uneven in different locations. To account for these differences we asked fisher leaders to estimate the extent of material damage observed in their organizations and caletas across seven items (later grouped into three components): boats and equipment (i.e., vessels component); pier, wincher, and office (i.e., caleta infrastructure component); and aquaculture, processing plants, and restaurant (i.e., productive/commercial infrastructure component). Informants expressed the level of damage using a 1 (=low) to 5 (=high) Likert-type scale presented to them in a card. The overall level of damage for each organization was calculated as an index consisting of the sum of average damage scores observed in each component, divided by the maximum theoretical damage (i.e., high damage in all components). We deliberately gave more weight to damage of vessels (i.e., one third of DAM) than to the infrastructure items (i.e., one ninth of DAM each), since it affects the very basis of the fishery activity. Details about data collection and index components are presented in Table 1.

Isolation (ISOL): Caletas are all located along the Bio-Bio coast, both near and integrated in cities where decision-making takes place, and in distant and less accessible rural areas (see Fig. 1). To capture how isolated organizations and their caletas are, we considered three important regional urban centers that concentrate key actors and sources of information and resources, namely the closest SERNAPESCA office (i.e., Coronel, Talcahuano or Tomé), SERNAPESCA headquarters, processing plants, the Regional Artisanal Fishery Association (i.e., Talcahuano), and the regional government, sectorial public agencies, and universities (i.e., Concepción). To account for differences in isolation, we averaged the distances (in kilometers) between the caleta where each organization operates and these three locations (see Table 1).

\section{Data analysis}

Data analysis was performed using Qualitative Comparative Analysis (QCA; Ragin 2008), which objective is to identify different causal conditions leading to a given outcome. It is based on set-theory and operates on membership scores of cases in sets that correspond to the different conditions and the outcome to be explained. Depending on the phenomenon of study and the kind of data available (e.g., dichotomous or partial cases membership), either crisp or fuzzy-set QCA (fsQCA) can be used. We apply the fsQCA analytical approach (performed with the software package QCA version 1.1-4; Dusa and Thiem 2014) since study variables present different levels and cases tend to be partial members in sets (scoring between 0 and 1). In QCA, the causes of the presence of an outcome are not assumed to be the same as those of its absence (i.e., asymmetry principle). Accordingly, and since we want to explain both more and less desirable recovery trajectories, we carried out two complementary analyses. The QCA process involves various multiple steps, which are extensively described elsewhere (Ragin 2008). We present the most relevant decisions made 
549 throughout the analysis, while a more detailed description of the fsQCA process and the 550 corresponding truth tables (Tables S3 and S4) are included in the Appendix. 
551 Table 1: Definition of outcome/dependent and conditions/explanatory variables

\begin{tabular}{|c|c|c|}
\hline Variables & Source of data & Questions \\
\hline $\begin{array}{l}\text { Post-disaster } \\
\text { recovery } \\
\text { trajectories } \\
\text { (outcome) }\end{array}$ & $\begin{array}{l}\text { Questionnaires / } \\
\text { key external } \\
\text { informants }^{\text {a }} \text { (and } \\
\text { fisher leaders }^{b} \text { ) }\end{array}$ & $\begin{array}{l}\text { In which stage do you consider each of the following } \\
\text { orgz. (or your org. }{ }^{\text {) }} \text { is now, after the } 2010 \text { tsunami, } \\
\text { as a productive unit? }\end{array}$ \\
\hline
\end{tabular}

Description (scale or measurement of raw data)

Anchor points

(5) Innovation: taken the opportunity to do new/different

Full memb.: 5

things.

Cross-over: 3.1

(4) Normalization: managed to recover a similar condition

Non-memb.: 0

they had before.

(3) Recovering: striving to move towards normalization.

(2) Stagnation: lacked continuity and dynamism in their efforts to recover.

(1) Recession: lost the capacities and qualities they had before.

Pre-disaster Base-line Which of the following institutions and organizations ${ }^{c}$ linking social information; have facilitated the development of your MEABRs? ${ }^{d}$

capital

(LINK08)

Post-disaster linking social

capital

(LINK13)

Level of

damage

(DAM)

Isolation

(ISOL)

questionnaires

fisher leaders

In a 1 (not important at all) to 4 (very important)

scale, how important have been each of the actors you identified?

Questionnaires / Which of the following institutions and organizations fisher leaders have facilitated the development of your MEABRs since 2012?

In a 1 (not important at all) to 4 (very important) scale, how important have they been?

Questionnaires / In a 1 (=low) to 5 (=high) scale, what was the level of fisher leaders impact suffered by your org in terms of: boats and equipment (i.e., vessels component); pier, wincher, and office (i.e., caleta infrastructure component); and aquaculture, processing plants, and restaurant (i.e., productive/commercial infrastructure component)?

Secondary information
How far is the caleta from: 1) the closest SERNAPESCA office (i.e., Coronel, Talcahuano or Tomé; 2) Talcahuano; 3) and Concepción?
Ego centered degree centrality measure (Borgatti and Everett 1997): total number of "facilitating" and "very important or important" relationships declared, expressed as a proportion of the theoretical maximum (from $0=$ minimum, to $1=$ maximum).

Ego centered degree centrality measure (see above).

Compound index including average impacts declared for each of the three components, and expressed as a proportion of the maximum theoretical damage (from $0=$ minimum, to $1=$ maximum).

Average distance to three relevant sources of information and resources (No. of kilometers)
Full memb.: 0.54 Cross-over: 0.31

Non-memb.: 0

Full memb.: 0.54 Cross-over: 0.31 Non-memb.: 0

Full memb.: 0.88 Cross-over: 0.33 Non-memb.: 0

Full memb.: $>98$ Cross-over: 30 Non-memb.: 0

${ }^{a}$ Asked to external informants for the assessment of post-disaster trajectories; ${ }^{b}$ Asked to fisher leaders to test the accuracy of criteria and responses. External and selfassessments show positive and significant correlation $(0.55 ; \mathrm{P}<0.05) ;{ }^{\mathrm{c}} \mathrm{A}$ roster with 26 potential counterparts was read to the interviewees; ${ }^{\mathrm{d}}$ The original question asked was: "Based on these three qualifiers (i.e. facilitating, hindering or not involved), how would you define the participation of the following institutions and organizations in the development of your MEABR?". We draw only on facilitating relationships to calculate LINK09/13 and the question has been rephrased to reflect this. 
We used quantitative scales for the calibration of variables and the definition of anchor points (Schneider and Wagemann 2012). For the outcome variable, we transformed the

559

560

561

562

563

564

565

566

567

568

569

570

571

572

573

574

575

576

577

578

579

580

581

582

583

584

585

586

587

588

589

590

591

592

593

594

original 1 to 5 scale into 0 to 1 fuzzy membership scores of the set of organizations with more desirable trajectories. For ISOL, average distances from caletas to closest cities (i.e., between 7 and $113 \mathrm{~km}$.) was calibrated into 0 to 1 scores to express organizations' fuzzy membership in the set of more isolated organizations. For LINK08, LINK13 and DAM, which were originally measured as proportions, no preliminary scale transformation was done.

Then, drawing on case knowledge and empirical distribution of data, anchor points for each variable were defined to establish which scores stand for full membership (=1), full nonmembership ( $=0)$, and for the cross-over or point of indifference $(=0.5)$. We consider fisher organizations with more desirable post-disaster performance as those assessed above the initial recovering trajectory (i.e., above score 3, thus we defined 3.1 as the cross-over); and the same threshold was used for less desirable trajectories. For linking SC, where predisaster levels represent the base-line for the follow-up measurement of post-disaster levels, we use the median observed in 2008 (i.e., above degree centrality of 0.31) as the cross-over point for LINK08 and LINK13. Most damaged organizations are considered those that have suffered damage levels above the median (i.e., 0.33), which implies all cases that had more than one third of the maximum potential damage. Finally, most isolated organizations are considered those cases whose distance from urban centers is, on average, higher than the median (i.e., $30 \mathrm{~km}$ ). Our definition of anchor points is summarized in the last column of Table 1.

We report QCA results following two minimization criteria, leading to solution terms with varied levels of complexity: the complex (i.e., the most conservative) and the parsimonious (e.g., the most simplistic) solution terms. For the parsimonious solution, all logically possible combinations of conditions that have not been observed among the empirical cases (termed logical reminders; Ragin 2008; see Appendix) are assumed to lead to a more desirable trajectory, whereas the opposite applies for the complex solution (further described in Appendix). QCA solutions are expressed using the following notation (e.g., Tables 3 and 4): conditions in upper-case letters represent the presence the condition (e.g. most damaged organizations =DAM), whereas conditions in lower-case letters stand for their absence (e.g., less isolated organizations =isol); symbols "*" and "+" mean logical AND and OR, respectively. Causal configurations resulting from QCA obtain a raw and a total coverage value that provide measurements of the empirical relevance of the solutions. Ranging from 0 to 1 , coverage values represent how much of the membership in the outcome is covered by the solutions (Ragin 2008). 
595

596

597

598

599

600

601

602

603

604

605

606

607

608

609

610

611

612

613

614

615

616

617

618

619

620

621

622

623

624

625

626

627

628

629

We also conducted a linear multivariable regression analysis, using SigmaPlot version 13.0, to evaluate the correlation between explanatory factors and the outcome variable from a conventional approach and to compare with results obtained from QCA.

\section{RESULTS}

The linear regression analysis (Table 2 ) shows that post-disaster linking SC is significantly related with post-disaster recovery trajectories $(p=0.021)$ and has an important effect on the variation of the dependent variable (coefficient= 2.626). There is no sign that other explanatory variables are connected with the outcome. Further, the adjusted $\mathrm{R}$ square value (0.22) indicates that there is high variability in the trajectories that cannot be explained by the model.

Table 2: Exploratory linear regression analysis of the four independent variables

\begin{tabular}{lccc}
\hline Variable & Coefficient & Std. error & $\mathrm{p}$-Value \\
\hline DAM & -1.125 & 1.204 & 0.364 \\
ISOL & -0.00793 & 0.00612 & 0.213 \\
LINK08 & -0.272 & 1.626 & 0.869 \\
LINK13 & 2.626 & 1.024 & $0.021^{*}$
\end{tabular}

Adjusted R-squared:

0.223

* Significant at 0.05

Results from the fsQCA are presented in Table 3 and 4. The analysis of sufficient conditions, using the complex minimization criterion, shows that more desirable post-disaster recovery trajectories can be achieved through three different combinations of causal variables (Table 3): 1) high levels of damage (DAM), low isolation (isol) and high levels of post-disaster linking SC (LINK13); 2) low isolation (isol) and high pre and post-disaster linking SC (LINK08 and LINK13); 3) low level of damage (dam), high isolation (ISOL) and a build-up in linking SC levels during the period (link08 and LINK13). The complete solution, including the three configurations, presents a consistency score of 0.875 . When consistency is higher than 0.8 , it means that the cause or causal combination is almost always sufficient for the specific outcome (Ragin 2008). The raw coverage of 0.75 indicates that three quarters of cases' membership in more desirable post-disaster trajectories can be explained by their membership in these three causal configurations. If the parsimonious minimization criterion is applied (Table 3), which leads to the most simplified solution, two causal pathways are obtained: 1) low isolation (isol) and high levels of post-disaster linking SC (LINK13); and 2) increased levels of linking SC levels between 2008 and 2013 (LINK13 and link08). 
630 Table 3: Causal configurations (CC) for membership ${ }^{a}$ in more desirable post-disaster livelihood

631 trajectories

\begin{tabular}{llllllc}
\hline $\begin{array}{l}\text { Minimization } \\
\text { criterion }\end{array}$ & CC & Configuration $^{\mathrm{b}}$ & Cons $^{\mathrm{c}}$ & Cov. $^{\mathrm{d}}$ & Cov. $^{\mathrm{e}}$ & $\begin{array}{c}\text { No. of } \\
\text { fisher orgs }\end{array}$ \\
\hline Complex & 1 & DAM*isol*LINK13 & 0.900 & 0.536 & 0.036 & 3 \\
& 2 & isol* LINK08*LINK13 $^{*}$ & 0.923 & 0.571 & 0.071 & 2 \\
& 3 & dam*ISOL*link08*LINK13 $^{*} 0.958$ & 0.548 & 0.119 & 1 \\
& For the complete solution: & 0.875 & 0.750 & & \\
Parsimonious & 4 & isol*LINK13 & 0.855 & 0.631 & 0.095 & 4 \\
& 5 & link08*LINK13 & 0.824 & 0.667 & 0.131 & 3 \\
& For the complete solution: & 0.821 & 0.762 & &
\end{tabular}

632

633

634

635

636

637

638

639

640

${ }^{a}$ According to Ragin (2008), inclusiveness score of 0.89 was used as the cut-off value to determine membership in CC (see Tables S3); ${ }^{b}$ DAM= most damaged orgs, ISOL= most geographically isolated orgs, LINK08= highest pre-disaster linking social capital, LINK13= highest post-disaster linking social capital; ${ }^{\mathrm{C}}$ Consistency score; ${ }^{\mathrm{d}}$ Coverage; ${ }^{\mathrm{e}}$ Unique coverage refers to how much of the outcome is solely explained by this condition (further described in e.g. Ragin 2008).

Table 4: Causal configurations (CC) for membership in less desirable post-disaster livelihood trajectories

\begin{tabular}{|c|c|c|c|c|c|c|}
\hline $\begin{array}{l}\text { Minimization } \\
\text { criterion }\end{array}$ & $\mathrm{CC}$ & Configuration $^{a}$ & Cons $^{b}$ & Cov.r $r^{c}$ & Cov.u ${ }^{d}$ & $\begin{array}{l}\text { No. of fisher } \\
\text { orgs }\end{array}$ \\
\hline \multirow{4}{*}{$\begin{array}{l}\text { Complex and } \\
\text { parsimonious }\end{array}$} & 1 & DAM*link13 & 0.967 & 0.460 & 0.048 & 5 \\
\hline & 2 & ISOL*link13 & 0.970 & 0.508 & 0.048 & 5 \\
\hline & 3 & LINK08*link13 & 0.946 & 0.556 & 0.063 & 5 \\
\hline & \multicolumn{2}{|c|}{$\begin{array}{l}\text { For the complete } \\
\text { solution: }\end{array}$} & 0.955 & 0.667 & & \\
\hline
\end{tabular}

${ }^{a}$ According to Ragin (2008), inclusiveness score of 0.87 was used as the cut-off value to determine membership in CC (see Table S4); ${ }^{\mathrm{b}} \mathrm{DAM}=$ most damaged orgs, ISOL= most geographically isolated orgs, LINK08= highest pre-disaster linking social capital, LINK13= highest post-disaster linking social capital; 'Consistency score; ${ }^{d}$ Coverage; ${ }^{\mathrm{e}}$ Unique coverage refers to how much of the outcome is solely explained by this condition (further described in e.g. Ragin 2008).

Table 4 presents the results of the analysis of sufficient conditions for less desirable postdisaster livelihood trajectories. This outcome could be achieved through three different causal pathways: 1) high levels of damage (DAM) and low levels of post-disaster linking SC (link13); 2) or high isolation (ISOL) and low levels of post-disaster linking SC (link13); 3) or 
decreased levels of linking SC during the period (link13 and LINK08). Note that the same result is obtained using either the complex or the parsimonious minimization criterion, which means that the solution term cannot be further reduced or simplified. Here, consistency score of the complete solution is also satisfactory (i.e., 0.955) and higher than conditions for more desirable trajectories. The raw coverage of 0.667 indicates that more than 66 percent of cases' membership in less desirable post-disaster trajectories can be explained by their membership in these three causal configurations. See Appendix, supplementary Figs. S1 and S2, for a visual representation of levels of consistency and coverage for the relation of sufficiency between more and less desirable trajectories and the solutions obtained from the fsQCA.

\section{DISCUSSION}

Results show that linking SC is a key factor of post-disaster recovery trajectories of fisher organizations. Significant $p$ value in the regression and presence of LINK13 in all fsQCA solutions indicate that having high levels of post-disaster linking SC is a critical requisite for development along more desirable trajectories (Table 2 and 3). Correspondingly, lack of linking SC after the tsunami (link13) is characteristic of all pathways conducive to less desirable trajectories (Table 4). These results are consistent with other similar studies in which supportive relationships with actors at higher levels have enabled the access to valuable information and resources that nurture local processes and foster positive responses to disasters among coastal communities (Pelling and High 2005; Munasinghe 2007; Aldrich 2010, 2012). While linking SC has been considered a key asset contributing to post-disaster recovery and sustainable livelihoods, its temporal dimension has been overlooked. However, our findings suggest this variation in SC over time can be important, by itself and in conjunction with other factors.

The relation between SC and disaster recovery suggested in previous studies is linear: the more SC the better the trajectories, and vice versa (Nakagawa and Shaw 2004; Munasinghe 2007; Aldrich 2010, 2012). However, in our study, SC does not explain the outcomes by itself. The low R-square in the regression (Table 2) and the presence of other factors in most of the fsQCA configurations (e.g., LINK08, DAM and ISOL in Tables 3 and 4) strongly suggest that post-disaster trajectories cannot be satisfactorily understood by looking only at linking SC. Furthermore, SC can fluctuate over time and the interplay between such fluctuation and other factors, and its effect on development trajectories, needs to be better understood. In what follows, the discussion focuses on the complex solutions presented above (Table 3, CC 1-3, and Table 4), and we only mention the parsimonious solutions when we consider it informative. 
694

695

696

697

698

699

700

701

702

703

704

705

706

707

708

709

710

711

712

713

714

715

716

717

718

719

720

721

722

723

724

725

726

727

728

729

730

731

732

733

Disaster literature has underlined the positive role of SC in post-disaster recovery (Nakagawa and Shaw 2004; Duxbury and Dickinson 2007; Aldrich 2012b; McCarthy 2014), but most studies have assumed a linear relation, with little attention to how variations in SC might increase or reduce its expected effect. Our study shows that such pre and post-disaster differences in SC levels represent an important factor of observed trajectories.

On the one hand, results indicate that increased (link08*LINK13) or maintained high (LINK08*LINK13) levels of linking SC represent sufficient conditions for more desirable trajectories (Table 3, CC 1, 3 and 5) - i.e. the build-up of linking SC can be sufficient condition for better trajectories by itself (if the most simplified solution is considered; Table 3, CC5). In the context of a disaster, increasing number of strong connections in fishers' social networks can provide access to new opportunities and help spread innovative ideas and a positive image of the organization among potential sources of support. This is the case of fisher organization (FO) 14 (Fig. 1), which showed a substantial increase of SC levels between 2008 and 2013, with new relationships with universities, fisheries consultants, and international NGOs. This organization's positive trajectory (i.e., normalization) refers to the recent improvement of its MEABR productivity by means of innovative aquaculture and resource restocking projects.

Pre-existing high linking SC maintained after the disaster also appears as a concurrent ingredient of more desirable trajectories (Table 3, CC 2). Fisher organizations with the capacity to keep relationships with actors at other levels alive, such as FO 4 in our study (Fig. 1), show increased likelihood of negotiating concrete support in a post-disaster situation. This organization has been able to implement a seaweed restocking project in their MEABR and to build the capacities to start up a seaweed drying/processing unit to add value to their produce. The organization has been considered an example of innovation by the SERNAPESCA and regional government. Maintained linking SC implies sustained access to, and flow of, resources and information from higher levels, which help resource users to achieve their goals in the aftermath of a disaster.

Inability of fisher organizations to maintain levels of linking SC (LINK08*link13) can lead to less desirable outcomes. Results show that losing linking SC after a destructive disaster is, by itself, a sufficient condition for falling into less desirable trajectories (Table 4, CC 3). Relying on a decreasing number of linking relationships not only implies reduced access to former sources of support and information but also has negative side-effects, both outside and within the organization. Potential supporters and donors, with whom organizations used to be connected in the past, are likely to perceive reduced and weakened relationships after the tsunami as a negative signal. Alternatively, it can be considered as a symptom of reduced organizational capacity and/or cohesiveness. These perceptions, whether justified or not, 
can lead to the breakdown of previous reciprocity and trust. Within organizations, the negative momentum created by the disaster and the loss of support can become a vicious circle. Beneficiaries' unmet expectations and disappointment with respect to former supporters may further weaken their capacity to act collectively. FO 2 (Fig 1.), for instance, has been historically described as a high performance organization with positive and balanced social, economic and ecological outcomes (Marín et al. 2012). They had a broad and diverse supportive network in the past that helped the implementation of innovative projects, unprecedented in the Bio-Bio region. However, substantial tsunami impacts in the village, changes in the leadership, and a dramatic decrease in post-disaster SC are linked to the general perception of poor performance and a discouraging trajectory (i.e., stagnation).

Our longitudinal analysis of the relationship between linking SC and development trajectories of small-scale fisher organizations suggests that temporal variations in this factor matter and can have both positive and negative effects on the internal capacity of resource users to recover and adapt to disasters. While we cannot determine the underlying cause of changes in SC, these changes were found to have concrete implications for the outcomes observed, implying that the benefits from SC are path-dependent. Past relationships affect current interactions and what people obtain from them. Variations in SC over time are directly associated with increased or decreased access to resources and information, and indirectly to the development or erosion of trust and reciprocity among actors. Moreover, current relationships among actors can be expected to shape future networks and associated expected benefits.

Policies can be critical in strengthening or weakening SC, but policies are rarely designed and implemented with consideration of their impact on social relationships (Woolcock 1998; Gelcich et al. 2006). Our findings stress the need to more explicitly take SC into account. Woolcock (1998) pinpoints three principles that underlie the reproduction of SC: levels increase with use; relationships of trust reinforced today will be amplified in the future; SC is more easily eroded than built-up. Accordingly, post-disaster recovery programs and development policies should pay special attention to explicitly incentivize the building and maintenance of linking SC, and to provide safeguards to avoid the loss of such facilitating relationships between impacted communities and actors at the regional and national levels.

\section{Concurrent internal and external factors explain post-disaster trajectories}

Knowledge about how external conditions can enhance or diminish the role of SC in post disaster recovery is limited yet the low R-square in the regression (Table 2) and the presence of other factors in most of the fsQCA configurations (e.g., LINK08, DAM and ISOL in Tables 3 and 4) strongly suggest that post-disaster trajectories cannot be satisfactorily understood by looking only at linking SC. It appears that varied levels of disaster damage and geographical 
isolation mediate the effects of linking SC on recovery trajectories, and that the combined effect of both external factors is also important.

Results show that, if linking SC levels are low, then both high damage and/or high isolation can lead fisher organizations towards less desirable trajectories (Table 4, CC 1, 2). Neither of these external factors, by themselves or in combination, lead to less desirable outcomes, thus it is their interplay with low levels of linking SC that is key to the observed outcomes. When damage is high (CC1) lack of strong cross-scale support make it difficult for organizations to pool large investment costs to revert severe disaster damage and material loss. FO 18 (Fig. 1) was heavily affected by the tsunami and had fairly low levels of SC in 2013. Despite having been considered one of the best fishing organizations in the region until recently (Marín et al. 2012), after the disaster they have not been able to recover their post-tsunami development pathway despite the efforts of their members and leadership (i.e., recession). Large investment costs associated with recovering from high damage represent a great barrier in a world of limited resources. In the absence of multiple support relationships with actors at higher levels, affected communities are unlikely to mobilize substantial financial resources from potential donors and agencies.

When a community is geographically isolated low linking SC makes it hard for organizations to bridge long distances to access information and resources necessary to fuel the recovery process. Geographical isolation can put affected communities in marginalized positions and exclude them from the map of post-disaster redevelopment assistance if they are not connected to a broad range of regional and national agencies. By contrast, if fisher organizations have high linking SC, then neither high levels of damage nor of isolation, by themselves, hamper the positive effect of high linking SC on fisher organizations' recovery trajectories, as shown in Table 3. For example, FO3 was severely impacted by the tsunami and operates nearby Tomé (see Fig. 1) and most of their vessels were lost and port infrastructure destroyed. Yet three years after the disaster, fishers had fully recovered their boats and equipment, diversified the species they catch, and were exploring ways to implement an aquaculture project with the support of various public and private institutions (i.e., normalization). Similarly, FO 14 provides a good illustration of high SC levels can mediate isolation (dam*ISOL). It had relatively low impacts from the tsunami but is located in a distant village (Fig. 1), yet despite this geographical barrier the organization mobilized resources and funding from other levels to innovate through aquaculture and fisheries management initiatives (possibly because damage levels were low). 


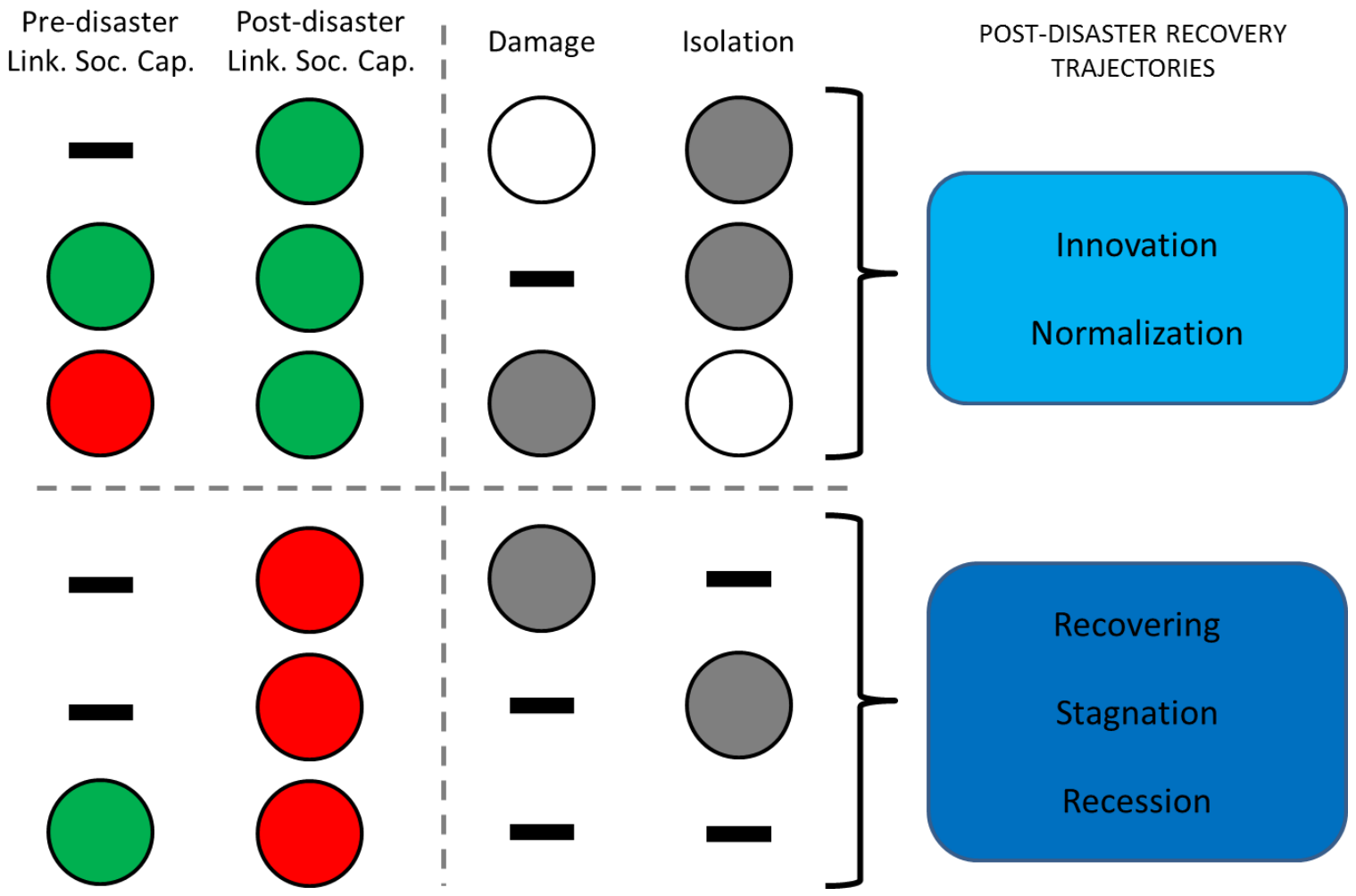

Figure 2: Multiple interplays between internal and external factors leading to different post-disaster recovery outcomes, based on QCA complex solutions. Green: high levels of linking social capital; Red:

low levels of linking social capital; Grey: high levels of damage or isolation; White: low levels of damage or isolation; Light blue: more desirable recovery trajectories; Blue: less desirable recovery trajectories; Dashes: absence of conditions in observed solutions.

Figure 2 (greyscale version in the Appendix, Fig. S3) summarizes our findings indicating that obstacles presented by high damage and high isolation can be off-set by the existence of strong facilitating relationships (high linking $\mathrm{SC}$ ) in a post-disaster context. However, at least one of these external factors had to be low, otherwise the ability to recover diminished. In other words, the patterns observed suggest that linking SC can overcome the expected negative effects of major material loss or geographical isolation, if both factors are not simultaneously present. The only possible combination of explanatory variables that might be sufficient to lead to a desirable trajectory, irrespectively of the levels of damage and isolation, was the increase of linking SC (CC5, parsimonious solution). However, due to limited diversity of our cases, there is no direct evidence of organizations facing high damage in very isolated localities that had been able to perform positive trajectories thanks to increased linking SC alone.

So why would it be so difficult to deal with the concurrency of high damage and high isolation together when these factors, in isolation, appear possible to overcome? Based on the previous examples, big investments to address severe damage (e.g., new port infrastructure) is more likely to be made near urban centers. We speculate that higher 
visibility of such investments, and the potential effects on agencies and donors' public opinion, might play a role as well. By contrast, investments in more distant locations are more likely to be made if damage and associated recovery costs are lower. We speculate that such cases represent good opportunities for supporters to invest in more innovative projects (e.g., restocking and aquaculture) where the costs and risks are lower and the potential return is high (e.g., replicability). Our findings stress the need to pay special attention to external factors that may foster more equitable recovery processes. Accordingly, post-disaster recovery and development initiatives should include special measurements to "level the field" among different groups and to explicitly bridge the gap for more isolated communities.

The study has several limitations that are worthwhile to mention. First, limited diversity is a common problem when using QCA when there are some combinations of conditions for which there is no evidence. This leads to open questions about the eventual outcomes under certain causal pathways. As mentioned above, we don't know what would be the trajectory of cases facing high damage and high isolation. Second, the results are influenced by the factors of recovery that were considered and by the operationalization of these factors. There are other potentially relevant factors of recovery not covered in the study, such as the level of education of individuals, and there are other types of SC, namely bonding and bridging. Further studies are necessary to explore the combined effect of and linking social capital in boosting/reducing capacities to recover from disasters and other social and ecological changes.

\section{Co-management networks help post-disaster recovery}

Studies have suggested that natural resource co-management networks increase community resilience to environmental change and other hazards (Adger et al. 2005; Tompkins and Adger 2004). Here, we operationalized and measured SC based on the networks developed in the context of marine resource co-management (Marín et al. 2012), to examine if these relationships, developed for a different purpose, can potentially be activated and utilized to promote post-disaster recovery. Results show that pre and post- disaster linking SC associated with the MEABR co-management policy can lead to an increased capacity for communities to act collectively and mobilize resources in a post-disaster situation in the contexts discussed above. However, one limitation of this study is the lack of a control group (i.e., disaster affected organizations not participating in the MEABR system), which prevents to test the actual effect of not engaging in co-management.

Interestingly the apparent positive role played by co-management networks in recovery trajectories derives not from the actual management of benthic marine resources (i.e., since we do not include management performance measures) but from the more or less formalized cross-scale social relationships established in that policy context. Various authors 
875 have emphasized the importance of investing in social infrastructure to produce sustainable

876 post-disaster recovery outcomes (Pomeroy et al. 2006; Duxbury and Dickinson 2007; Aldrich

877 2012b). In our study, co-management provides the platform for collaborative relationships -

878 useful for post-disaster recovery - to develop. Unlike other cases, where linking SC has been

879 used by elites to reinforce their privileges and to exclude others (Murphy 2007), in Chile the

880 existence of stable community-based fisher organizations with elected leadership opens up

881 the space for more accountable flow and exchange of support across scales. The expected

882 positive benefits from linking SC are more likely to produce more effective and equitable

883 results if people are organized and have the capacity to act collectively. Our findings suggest

884 that investing in permanent resource management social infrastructure can have positive

885 externalities in the face of an unexpected disaster. A key finding is therefore the fact that

886 that SC developed for the purpose of co-management of natural resources can actually

887 promote desirable post-disaster trajectories.

888

889

890

891 
892

893

894

895

896

897

898

899

900

901

902

903

904

905

906

907

908

909

910

911

912

913

914

915

916

917

918

919

920

921

922

923

924

925

926

927

928

929

930

\section{REFERENCES}

Aburto, J., Thiel, M., Stotz, W. (2009). Allocation of effort in artisanal fisheries: The importance of migration and temporary fishing camps. Ocean \& Coastal Management, 52(12), 646-654. doi:10.1016/j.ocecoaman.2009.10.004

Adger, W. N. (2003). Social capital, collective action, and adaptation to climate change. Economic Geography, 79(4), 387-404.

Adger, W. N. (2006). Vulnerability. Global Environmental Change, 16(3), 268-281. doi:10.1016/j.gloenvcha.2006.02.006

Adger, W. N., Hughes, T. P., Folke, C., Carpenter, S. R., Rockström, J. (2005). Social-ecological resilience to coastal disasters. Science, 309(5737), 1036-9. doi:10.1126/science.1112122

Aldrich, D. P. (2010). The power of people: social capital's role in recovery from the 1995 Kobe earthquake. Natural Hazards, 56(3), 595-611. doi:10.1007/s11069-010-9577-7

Aldrich, D. P. (2011). The Externalities of Strong Social Capital: Post-Tsunami Recovery in Southeast India. Journal of Civil Society, 7(1), 81-99. doi:10.1080/17448689.2011.553441

Aldrich, D. P. (2012a). Building resilience: Social capital in post-disaster recovery. University of Chicago Press.

Aldrich, D. (2012b). Social, Not Physical, Infrastructure: The Critical Role of Civil Society in Disaster Recovery. Disasters, 36(3), 398-419.

Alexander, B., Chan-Halbrendt, C., Salim, W. (2006). Sustainable livelihood considerations for disaster risk management: Implications for implementation of the Government of Indonesia tsunami recovery plan. Disaster Prevention and Management, 15(1), 31-50. doi:10.1108/09653560610654220

Berkes, F. (2007). Understanding uncertainty and reducing vulnerability: lessons from resilience thinking. Natural Hazards, 41(2), 283-295. doi:10.1007/s11069-006-9036-7

Blaikie, P., Cannon, T., Davis, I., Wisner, B. (2004). At Risk: Natural Hazards, People's Vulnerability and Disasters. Routledge, London. 
Bodin, Ö., Crona, B. (2008). Management of Natural Resources at the Community Level: Exploring the Role of Social Capital and Leadership in a Rural Fishing Community. World Development, 36(12), 2763-2779. doi:10.1016/j.worlddev.2007.12.002

Bodin, Ö., Crona, B. I. (2009). The role of social networks in natural resource governance: What relational patterns make a difference? Global Environmental Change, 19(3), 366374. doi:10.1016/j.gloenvcha.2009.05.002

Borgatti, S., Jones, C., Everett, M. (1998). Network measures of social capital. Connections, 21(2), 27-36.

Bourdieu, P. (1986). The forms of capital. Handbook of Theory and Research for the Sociology of Education, 241, 241-258. doi:10.1002/9780470755679.ch15

Carpenter, S., Arrow, K., Barrett, S., Biggs, R., Brock, W., Crépin, A.-S., ... Zeeuw, A. (2012). General Resilience to Cope with Extreme Events. Sustainability, 4(12), 3248-3259. doi:10.3390/su4123248

Castilla, J. C., Manriquez, P., Alvarado, J., Rosson, A., Pino, C., Espoz, C., Soto, R., Oliva, D., Defeo, O. (1998). Artisanal "caletas" as units of production and co-managers of benthic invertebrates in Chile. Canadian Special Publication of Fisheries and Aquatic Sciences, $125,407-413$.

Castilla, J. C., Manríquez, P. H., Camaño, A. (2010). Effects of rocky shore coseismic uplift and the 2010 Chilean mega-earthquake on intertidal biomarker species. Marine Ecology Progress Series, 418, 17-23. doi:10.3354/meps08830

Coleman, J. S. (1988). Social Capital in the Creation of Human Capital. American Journal of Sociology, 94(1988), S95. doi:10.1086/228943

Costanza, R., Farley, J. (2007). Ecological economics of coastal disasters: Introduction to the special issue. Ecological Economics, 63(2-3), 249-253. doi:10.1016/j.ecolecon.2007.03.002

Cutter, S. L., Boruff, B. J., Shirley, W. L. (2003). Social vulnerability to environmental hazards. Social science quarterly, 84(2), 242-261.

Cutter, S. L., Ash, K. D., Emrich, C. T. (2014). The geographies of community disaster resilience. Global Environmental Change, 29, 65-77.

Diamond, J. (2005). Collapse: How societies choose to fail or succeed. Penguin, New York. 
972

973

974

975

976

977

978

979

980

981

982

983

984

985

986

987

988

989

990

991

992

993

994

995

996

997

998

999

1000

1001

1002

1003

1004

1005

1006

1007

1008

1009

1010

1011

1012

Dusa, A., Thiem, A. (2014). Qualitative Comparative Analysis. R Package Version 1.1-4. URL: http://cran.r-project.org/package=QCA.

Duxbury, J., Dickinson, S. (2007). Principles for sustainable governance of the coastal zone: in the context of coastal disasters. Ecological Economics, 63(2), 319-330.

Frankenberg, E., Sikoki, B., Sumantri, C., Suriastini, W., Thomas, D. (2013). Education, Vulnerability, and Resilience after a Natural Disaster. Ecology and Society 18(2): 16. http://dx.doi.org/10.5751/ES-05377-18021618(2)

Fritz, H. M., Petroff, C. M., Catalán, P. a., Cienfuegos, R., Winckler, P., Kalligeris, N., et al. (2011). Field Survey of the 27 February 2010 Chile Tsunami. Pure and Applied Geophysics, 168, 1989-2010. doi:10.1007/s00024-011-0283-5

Gelcich, S., Edwards-Jones, G., Kaiser, M. J. (2005). Importance of attitudinal differences among artisanal fishers toward co-management and conservation of marine resources. Conservation Biology, 19(3), 865-875. doi:10.1111/j.1523-1739.2005.00534.x

Gelcich, S., Edwards-Jones, G., Kaiser, M. J., Castilla, J. C. (2006). Co-management policy can reduce resilience in traditionally managed marine ecosystems. Ecosystems, 9(6), 951966.

Gelcich, S., Hughes, T. P., Olsson, P., Folke, C., Defeo, O., Fernandez, M., et al. (2010). Navigating transformations in governance of Chilean marine coastal resources. Proceedings of the National Academy of Sciences of the United States of America, 107(39), 16794-16799. doi:10.1073/pnas.1012021107

Goldstein, B. E. (2008). Skunkworks in the embers of the Cedar fire: Enhancing resilience in the aftermath of disaster. Human Ecology, 36(1), 15-28. doi:10.1007/s10745-007-91336

Grafton, R. Q. (2005). Social capital and fisheries governance. Ocean \& Coastal Management, 48, 753-766. doi:10.1016/j.ocecoaman.2005.08.003

Gunderson, L. (2010). Ecological and Human Community Resilience in Response to Natural Disasters. Ecology and Society, 15(2), 18. [online] URL: http://www.ecologyandsociety.org/vol15/iss2/art18/

Haas, J.E., R.W. Kates, M.J. Bowden (1977) Reconstruction following Disaster. Cambridge, MA: MIT University Press. 
Ingram, J. C., Franco, G., Rio, C. R., Khazai, B. (2006). Post-disaster recovery dilemmas: challenges in balancing short-term and long-term needs for vulnerability reduction. Environmental Science \& Policy, 9(7-8), 607-613. doi:10.1016/j.envsci.2006.07.006

Jaramillo, E., Dugan, J. E., Hubbard, D. M., Melnick, D., Manzano, M., Duarte, C., et al. (2012). Ecological Implications of Extreme Events : Footprints of the 2010 Earthquake along the Chilean Coast. PloS One 7(5). doi:10.1371/journal.pone.0035348

Kates, R.W., Pijawka, D. (1977). From rubble to monument: the pace of reconstruction. In J.E. Haas, R.W. Kates and M.J. Bowden (Eds.) Disaster and Reconstruction, M.I.T. Press, Cambridge, Massachusetts: 1-23.

Krishna, A. (2002). Active social capital: Tracing the roots of development and democracy. Columbia University Press.

Leitch, A. M., Bohensky, E. L. (2014). Return to "a new normal": Discourses of resilience to natural disasters in Australian newspapers 2006-2010. Global Environmental Change, 26, 14-26. doi:10.1016/j.gloenvcha.2014.03.006

Lakon, C. M., Godette, D. C., Hipp, J. R. (2008). Network-based approaches for measuring social capital. In Social capital and health (pp. 63-81). Springer New York.

Lin, N. (2001). Building a network theory of social capital, Connections 22(1), 3-29.

Manyena, S. B. (2006). The concept of resilience revisited. Disasters, 30(4), 434-450.

Marín, A., Berkes, F. (2010). Network approach for understanding small-scale fisheries governance: The case of the Chilean coastal co-management system. Marine Policy, 34(5), 851-858. doi:10.1016/j.marpol.2010.01.007

Marín, A., Gelcich, S., Araya, G., Olea, G., Espíndola, M., Castilla, J. C. (2010). The 2010 tsunami in Chile: Devastation and survival of coastal small-scale fishing communities. Marine Policy, 34(6), 1381-1384. doi:10.1016/j.marpol.2010.06.010

Marín, A., Gelcich, S., Castilla, J. C., Berkes, F. (2012). Exploring Social Capital in Chile 's Coastal Benthic Comanagement. Ecology and Society, 17(1), 13. doi:10.5751/ES-04562170113

Maru, Y. T., Stafford Smith, M., Sparrow, A., Pinho, P. F., Dube, O. P. (2014). A linked vulnerability and resilience framework for adaptation pathways in remote 
disadvantaged communities. Global Environmental Change, 28, 337-350. doi:10.1016/j.gloenvcha.2013.12.007

Masten, A. S., J. Obradović (2008). Disaster preparation and recovery: lessons from research on resilience in human development. Ecology and Society 13(1): 9. [online] URL: http://www.ecologyandsociety.org/vol13/iss1/art9/

McCarthy, J. F. (2014). Using community led development approaches to address vulnerability after disaster: Caught in a sad romance. Global Environmental Change, 27, 144-155.

Mendonça, D., Wallace, W. A. (2004). Studying organizationally-situated improvisation in response to extreme events. International Journal of Mass Emergencies and Disasters, 22(2), 5-30.

Miller, F., Thomalla, F., Downing, T., Chadwick, M. (2006). Resilient ecosystems, healthy communities: Human health and sustainable ecosystems after the December 2004 tsunami. Oceanography, 19(2), 50-51.

Mimura, N., Yasuhara, K., Kawagoe, S., Yokoki, H., Kazama, S. (2011). Damage from the Great East Japan Earthquake and Tsunami - A quick report. Mitigation and Adaptation Strategies for Global Change, 16(7), 803-818. doi:10.1007/s11027-011-9297-7

Morton, R. A., Gelfenbaum, G., Buckley, M. L., Richmond, B. M. (2011). Geological effects and implications of the 2010 tsunami along the central coast of Chile. Sedimentary Geology, 242(1-4), 34-51. doi:10.1016/j.sedgeo.2011.09.004

Mouw, T. (2006). Estimating the causal effect of social capital: A review of recent research. Annual review of sociology, 79-102.

Munasinghe, M. (2007). The importance of social capital: Comparing the impacts of the 2004 Asian Tsunami on Sri Lanka, and Hurricane Katrina 2005 on New Orleans. Ecological Economics, 64(1), 9-11. doi:10.1016/j.ecolecon.2007.05.003

Murphy, B. L. (2007). Locating social capital in resilient community-level emergency management. Natural Hazards, 41(2), 297-315. doi:10.1007/s11069-006-9037-6

Nakagawa, Y., Shaw, R. (2004). Social Capital: A Missing Link to Disaster Recovery. International Journal of Mass Emergencies and Disasters, 22(1), 5-34. 
National Research Council (2012). Disaster Resilience: A National Imperative. The U.S. National Academy of Sciences: The National Academies Press: Washington, DC.

Olsson, P., Galaz, V. (2012). Social-ecological innovation and transformation, in A. Nicholls and A. Murdock (Eds.) Social innovation: blurring boundaries to reconfigure markets. Palgrave Macmillan, Basingstoke, UK.

Palermo, D., Nistor, I., Saatcioglu, M., Ghobarah, A. (2013). Impact and damage to structures during the 27 February 2010 Chile tsunami. Canadian Journal of Civil Engineering, 40(8), 750-758.

Payne, H., Castilla, J. C. (1994). Socio-biological Assessment of Common Property Resources Management: Small SCale Fishing Unions in Central Chile. Out of the Shell, 4(3), 10-14.

Pelling, M., High, C. (2005). Understanding adaptation: What can social capital offer assessments of adaptive capacity? Global Environmental Change, 15(4), 308-319. doi:10.1016/j.gloenvcha.2005.02.001

Pomeroy, R. S., Ratner, B. D., Hall, S. J., Pimoljinda, J., Vivekanandan, V. (2006). Coping with disaster: Rehabilitating coastal livelihoods and communities. Marine Policy, 30(6), 786793. doi:10.1016/j.marpol.2006.02.003

Portes, A., Landolt, P. (2000). Social Capital: Promise and Pitfalls of its Role in Development. Journal of Latin American Studies, 32, 529-547. doi:10.1017/S0022216X00005836

Pretty, J. (2003). Social capital and the collective management of resources. Science, 302(2003), 1912-1914. doi:10.1126/science.1090847

Putnam, R. D. (2001). Bowling alone: The collapse and revival of American community. Simon and Schuster, New York.

Ragin, C.C. (2008). Redesigning Social Inquiry: Fuzzy Sets and Beyond. University of Chicago Press, Chicago.

Ramirez-Sanchez, S., Pinkerton, E. (2009). The impact of resource scarcity on bonding and bridging social capital: the case of fishers' information-sharing networks in Loreto, BCS, Mexico. Ecology and Society, 14(1), 22.

Régnier, P., Neri, B., Scuteri, S., Miniati, S. (2008). From emergency relief to livelihood recovery: Lessons learned from post-tsunami experiences in Indonesia and India. 
Disaster Prevention and Management, 17(3), 410-430.

doi:10.1108/09653560810887329

Santha, S. D. (2014). Adaptation to coastal hazards : the livelihood struggles of a fishing community in Kerala, India. Disasters, 39(1), 69-85. doi:doi:10.1111/disa.12094

Servicio Nacional de Pesca y Acuicultura (2013a). Anuarios Estadísticos de Pesca 2009-2013. Sistema de Información y Estadística Pesquera del Servicio Nacional de Pesca, Valparaiso, Chile. [online] URL: http://sernapesca.cl/index.php?option=com_remository\&ltemid=54\&func=select\&id=2

Servicio Nacional de Pesca y Acuicultura (2013b). Registro Pesquero Artesanal de Pescadores y Embarcaciones, Valparaiso, Chile. [online] URL: http://www.sernapesca.cl/index.php?option=com_remository\&Itemid=246\&func=fileinf o\&id=7861

Schneider, C. Q., Wagemann, C. (2012). Set-theoretic methods for the social sciences: A guide to qualitative comparative analysis. Cambridge University Press.

Schumann, S. (2010). A tenuous triumvirate: The role of independent biologists in Chile's comanagement regime for shellfish. Marine Policy, 34, 133-138. doi:10.1016/j.marpol.2009.05.004

Skoufias, E. (2003). Economic Crises and Natural Disasters: Coping Strategies and Policy Implications. World Development, 31(7), 1087-1102. doi:10.1016/S0305750X(03)00069-X

Smith, K. (2013). Environmental hazards: assessing risk and reducing disaster. Routledge.

Szreter, S., Woolcock, M. (2004). Health by association? Social capital, social theory, and the political economy of public health. International Journal of Epidemiology, 33(4), 650667. doi:10.1093/ije/dyh013

Thorburn, C. (2009). Livelihood recovery in the wake of the tsunami in Aceh. Bulletin of Indonesian Economic Studies, 45(1), 85-105.

Tierney, K. (2013). “Only Connect!” Social Capital, Resilience, and Recovery. Risk, Hazards \& Crisis in Public Policy, 4(1), 1-5. doi:10.1002/rhc3.20

Tompkins, E. L., and Adger, W. (2004). Does adaptive management of natural resources enhance resilience to climate change?. Ecology and society, 9(2), 10. 
Turner, B. L. (2010). Vulnerability and resilience: Coalescing or paralleling approaches for sustainability science? Global Environmental Change, 20(4), 570-576. doi:10.1016/j.gloenvcha.2010.07.003

Vargas, G., Farías, M., Carretier, S., Tassara, A., Baize, S., Melnick, D. (2011). Coastal uplift and tsunami effects associated to the $2010 \mathrm{M}$ w 8 . 8 Maule earthquake in Central Chile. Andean Geology, 38(1), 219-238.

Walker, B., Hollin, C. S., Carpenter, S. R., Kinzig, A. (2004). Resilience, adaptability and transformability in social-ecological systems. Ecology and Society, 9(2), 9.

Woolcock, M. (1998). Social capital and economic development: Toward a theoretical synthesis and policy framework. Theory and society, 27(2), 151-208.

Woolcock, M. (2001). The place of social capital in understanding social and economic outcomes. Canadian Journal of Policy Research, 2(2000), 1-35.

Woolcock, M. (2002). Social capital in theory and practice: Where do we stand? In T. K. and S. R. J. Isham (Eds.) (pp. 18-39). Chetlenham, UK: Edward Elgar.

Young, O. R., Lambin, E. F., Alcock, F., Haberl, H., Karlsson, S. I., McConnell, W. J., ... \& Verburg, P. H. (2006). A portfolio approach to analyzing complex human-environment interactions: institutions and land change. Ecology and Society, 11(2), 31.

Zanuttigh, B. (2014). Features Common to Different Hydrometeorological Events and Knowledge Integration. Hydrometeorological Hazards: Interfacing Science and Policy, 49-81. 